\title{
Pursuit of fairness in household financial arrangements among young middle-class couples in Poland
}

\author{
Marta Olcoń-Kubicka
}

Institute of Philosophy and Sociology of the Polish Academy of Sciences, Poland

\begin{abstract}
Drawing on ethnographic research into household money practices among young middle-class couples in Warsaw, Poland, this article shows that normative concerns about the fair use of domestic money shape household budgeting rules. The practical division of funds into 'mine', 'yours' and 'ours' reflects what couples running a household together consider morally right. Focusing on couples' practical and moral reasoning, I show the set of expectations and the moral logic they employ to achieve fairness in their household financial arrangements. The analysis of two models of domestic money allocation - the 50-50 model, which is based on a couple's equal contributions, and the joint-money model, which involves a couple's recognition of mutual obligations - highlights how fairness is articulated in rules about equality, independence and solidarity. By studying couples through time as they experience significant life changes, I show how the rules of fairness come to be challenged and how what is considered fair is questioned or even contested. I argue that turning points such as taking out a mortgage together or having a child produce new expectations and imaginaries about the future and prompt couples to question the rules of fairness and consequently to change their money practices.
\end{abstract}

\section{Keywords}

Money, household, budgeting, couples, financial arrangement, morality

Corresponding author:

Marta Olcoń-Kubicka, Institute of Philosophy and Sociology at the Polish Academy of Sciences, 72 Nowy Świat, 00-330 Warszawa, Poland.

Email: molcon-kubicka@ifispan.waw.pl

\section{MPIfG Journal Article}

Marta Olcoń-Kubicka: Pursuit of Fairness in Household Financial Arrangements Among Young Middle-Class Couples in Poland. In: Journal of Consumer Culture 20(2), 156-174 (2020). Sage Publications

The original publication is available at the publisher's web site: https://doi.org/10.1177/1469540519891272

The MPIfG Journal Articles series features articles by MPIfG researchers and visiting scholars published in peer-reviewed journals. Max Planck Institute for the Study of Societies (MPIfG) Cologne | www.mpifg.de 


\section{Introduction}

Krzysztof and Ania live in a Warsaw apartment bought on credit and are raising two children together. Ania is returning to work after a year of paid maternity leave, and they are discussing how to organise their future spending, specifically, paying a nanny to look after their children. Previously, Krzysztof paid expenses such as rent, mortgage payments and large expenditures (e.g. furniture), while Ania was responsible for groceries. 'The bills are Krzysztof's and the day-to-day expenses are mine', Ania explains. As they discuss the nanny's wage, Krzysztof insists on sharing that expense equally, so they both take responsibility. Ania strongly disagrees, 'Why even make this sort of calculation?! We are a family, not business partners, and we have joint money, anyway'.

Ania and Krzysztof's conversation illustrates the key contention of this article: couples organise their domestic budgets in many different ways - not only to satisfy their needs, but also to pursue an idealised family life. Creating financial arrangements involves budgeting, earning, spending, saving, paying the bills, shopping, talking about money and sharing an understanding of the rules governing these practices. Money management reflects values, and norms, about the 'right' use of funds in a domestic setting. Scholars researching household moral economies have shown the moral dimensions of household budgeting (Zaloom, 2015; Zelizer, 1997). Money management, like consumption (Miller, 2005; Pellandini-Simányi, 2014, 2016; Ross, 2014; Schor et al., 2010; Slater, 2009; Warde, 2017), becomes an area for the practice of ethics in everyday life.

In this article, I will demonstrate that household budgeting is constrained by moral convictions and expectations and that couples mobilise non-economic rationalisations for the 'good' use of money. Based on ethnographic research on the household finances of young middle-class couples in Warsaw, Poland, I present two models of fairness: the 50-50 model, based on a couple's desire for equality and independence, and the joint-money model, which involves a couple's recognition of mutual obligation. By examining situations that make household members question what 'good' money use is, we see how couples make sense of these rules.

Money management rules are especially important for young couples who are beginning their life together and establishing new financial arrangements. Participants in this study are the 'first free market generation', that is, the first generation to grow up during Poland's post-1989 political, social and economic transformation into a market economy. They have been exposed to new types of risks and uncertainty concerning finance and everyday consumption. In a newly market-based society, they have had to develop different strategies for negotiating between love, and money; market, and non-market, transactions. In consideration of Mary Douglas' ideas (cf. 1991: 296) on how household members achieve solidarity, and to what extent it can be measured, I focus in this article on how couples combine calculation with moral judgement. Specifically, I will examine couples' practical, and moral, reasoning about what is 'yours', 'mine' and 'ours', and how these normative concerns shape time-limited, dynamic financial arrangements. 
I will argue that negotiations concerning financial arrangements are driven by a lay morality (Sayer, 2011), which our interlocutors framed as 'fairness'. The fairness of household financial arrangements is not a matter of objective justice, but of having a sort of agreement, or a 'social contract' (Rawls, 1971), on domestic level, and striving to generate the mutual feeling that specific decisions about money management are right, fair and just. Or, as one participant explained, 'everything should be fair, clear, and transparent'. Therefore, a couple's financial arrangements demonstrate their moral respectability through conformity to particular norms such as equality, independence or solidarity.

Previous work on models of money allocation between married, or cohabiting, men and women (Burgoyne, 1990; Ibragimova and Guseva, 2017; Kenney, 2006; Pahl, 1989; Singh, 1997; Vogler, 1998; Vogler and Pahl, 1994) used mostly national surveys and interviews and focused on categories such as gender, control, power and inequalities. In contrast, my perspective offers an ethnographic approach to household money practices. This article attends to household financial arrangements in formation, emphasising the role of moral reasoning. Rather than provide a whole spectrum of money management models in Poland, I focus on discursive practices (Sonnenberg, 2008) that enable financial arrangements to emerge and be transformed. In what follows, I will show how, and why, household budgeting rules are shaped by normative concerns, and how these practices are renegotiated in connection with significant life events.

My approach is theoretically informed by the culturally oriented sociology of money (Bandelj et al., 2017; Carruthers and Espeland, 1998; Steiner, 2015; Wherry, 2016, 2017; Zelizer, 1997, 2005, 2011), which provides an analytical lens for studying household moral economy. Following Viviana Zelizer (2012), I frame the negotiations of household financial arrangements in terms of ongoing 'relational work', in which couples pursue fairness by matching their money practices to the kind of relationship they hope to achieve. By focusing on people's practical, and moral, reasoning, I show the wide variety of expectations, and moral logics, used to achieve fairness in their household financial arrangements. Adopting a dynamic approach to relational work, I studied couples over time, as they experienced significant life changes, with emphasis upon situations where rules of fairness are challenged, and what was considered fair is questioned, or contested. I argue that certain turning points give rise to new expectations, and new imaginaries about the future, prompting couples to question the fairness of their previous rules, and, consequently, to change their money practices.

Analysis of the two models of allocating money (50-50 and joint-money) highlights differences between couples' moral, and practical, reasoning, particularly how 'fairness' is articulated in rules about equality, independence and solidarity. I show how normative concerns around these values shape household money practices. Then, I discuss how these rules of everyday practice are challenged by significant life changes (e.g. a mortgage or having children), and how couples cope with these changes. 


\section{Research and field sites}

This article draws on a broader ethnographic research project (2014-2017) on money practices involving 28 young, middle-class households in Warsaw, and its suburbs (Halawa and Olcoń-Kubicka, 2018; Olcoń-Kubicka, 2016; Olcoń-Kubicka and Halawa, 2018). These couples' money practices help us better understand the mutual, and economic, strategies of a young generation living in a society whose market economy is less than 30 years old. Economic, and financial, matters acquired a new urgency for Poles in connection with the privatisation of Polish industry and services (Dunn, 2004); the promulgation of liberalism; and the rise of individualism, entrepreneurship and private property, especially home ownership (Halawa, 2015). As in other post-communist countries (Patico, 2005), the importance of money in social life gradually increased until it became a source of prestige; an indicator of success in life; and an important reference point in evaluating life satisfaction (cf. Marody, 1991: 39). While under the communist system, both men and women were active in the labour market, the emerging market economy transformed gender relations by valuing men's work more highly (Marody and GizaPoleszczuk, 2000). Simultaneously, the family remains a crucial value, and reference group, for individual life strategies (Giza-Poleszczuk and Poleszczuk, 2004; Marody, 1995). After Poland became a member of the EU in 2004, new social expectations of 'living normally' emerged (Galasińska and Galasiński, 2010). Western, European lifestyles became aspirational reference points, especially for the new emerging middle class, resembling other countries in the region (Tóth and Simányi, 2006). Meanwhile, the private banking sector actively worked to stimulate Polish society's consumption desires (Rona-Tas and Guseva, 2014). However, low earnings (compared to the European average), a sense of insecurity in regard to the labour market, and consumer aspirations remaining from the late socialist era (Zalewska, 2017), have presented significant barriers to achieving new standards for a 'normal life'.

In this context, couples' money practices are shaped by concerns about 'normal', 'right' and 'fair' use of money. Early in my fieldwork, 'fairness' appeared as a key feature of domestic money practices. Proceeding inductively, I focused on this emerging theme, which was explicitly raised, and emphasised, by research participants. Fieldwork mainly involved dyadic interviews with both partners in a couple, which I conducted with a male co-investigator. This approach allowed us to obtain a couple's joint perspective on financial arrangements and to observe partners' dynamic exchanges of opinion. In addition, participants kept financial diaries for 2 weeks, and we conducted individual interviews, and object-centred interviews, with couples who use budgeting software. I conducted individual interviews with women, while my co-investigator interviewed men. All participants were 21-37 years old, had higher degrees, were active on the labour market (or were on maternity leave) and had a monthly net household income between 5000 and 13,000 PLN (€1200-3000).

The project involved both married and cohabiting couples, selected because they had experienced a significant life change within a year of the first interview: moving in together, taking out a mortgage together or having a baby. However, as the 
research was longitudinal, and based on multiple (3-5) home visits at intervals ranging from 2 weeks to a year and a half, we observed further life changes. Couples married, had children or moved to a new home. Repeated visits allowed us to register the changes occurring in money practices, and the shifts from one model of financial arrangement to another, along with changing relationship dynamics. Further shifts were also reported by the couples themselves as they shared stories from their past.

\section{The rules of fairness, the fairness of rules}

This section examines two models for allocating money: the 50-50 model and the joint-money model. In both models, couples attempt to match money practices and conceptions of fairness. My analysis focuses on key rules in each model, money practices, and challenges that require a couple to change their model or that call the criteria of fairness into question. I argue that spending and saving rules, as well as the division of money into 'mine', 'yours' and 'ours', reflect time-bound, grounded, moral logics. By practising a certain model of money allocation, couples consider the moral dimensions of financial arrangements by defining their practices as 'right', or 'wrong', at that particular moment. Later, I show how certain situations necessitate in moral reasoning, as couples strive to balance equality, independence and solidarity in their financial arrangements.

\section{Being equal and independent: The 50-50 rule}

This model is practised mainly by newer couples in informal, cohabiting relations. In 50-50 arrangements, both partners contribute equally to household expenses, while keeping the rest of their money separate, in personal bank accounts, outside the other partner's control. Equality and independence are the rules of fairness that shape this model. Dividing expenses equally is a rule that is easy to suggest in a relationship's early stages. 'We had to have a rule to follow', says Piotr about the beginning of his relationship with Ula. This approach relies on a simple arithmetic division of expenses. When monthly rent, or mortgage instalments, must be paid, either both partners chip in, and cash appears physically on the table, or one of them pays the rent, and the other immediately returns half the amount via a bank transfer. For each partner, it is important to keep track of these transfers, to keep each other informed of current balances and to account for expenses when necessary. Typically, the accounting unit is one month, because wages are paid monthly.

Alongside regular bills, couples try to share expenses connected with living together, such as groceries. Thus, the next important element of the 50-50 model is creating a joint budgeting area, while still retaining financial separateness. Whether chipping in to cover shared expenses, or taking turns paying, each partner must contribute the same amount of money. This negotiated, agreed-upon area clearly separates joint, and private, expenditures, and requires clear-cut boundaries about what constitutes a shared expense. Couples use earmarking systems to indicate what 
can, and cannot, be financed with joint money. For instance, cleaning supplies are an expense that should be shared equally, but cosmetics (especially more expensive women's ones) are a private expense. Outside the negotiated joint area, partners retain their financial independence; private funds are categorised as 'mine', to be spent as desired. Personal funds, and spending, remain outside the other partner's control.

Having a small, shared area of expenditure necessitates a regular settling of 'debts' between partners, via regular bank transfers, or cash. Settling grocery expenses is a common reason for such 'debt' transfers. In order to keep the 5050 rule where each partner has money in a separate, private account, each grocery trip has to be accounted for, and shared equally. Maja and Roman, a married couple, remember that before marriage they divided products printed on receipts into three categories: 'shared', 'Maja's' and 'Roman's'. They settled who owed what to whom immediately after the transaction, or after returning home, otherwise a debt would arise, especially if the purchase was expensive.

Precise settling is more typical of fresh relationships; the longer couples are together, the less they tend to perform exact, and tiresome, calculations. Instead, couples round sums up or down, so the amounts are 'more or less' what is required. Partners still attempt to repay 'debts' to each other, but, as they emphasise, not every last penny is accounted for, since that would be 'embarrassing'. In a 50-50 arrangement, couples begin to avoid precise calculations so the relationship does not seem like transactions between business partners. Even if couples follow an exact 50-50 division with all their transactions, they keep it between themselves, and avoid settling accounts in front of others. They believe such debts are private matters, and it looks bad to settle them publicly. This is how Dagmara describes her agreement with her fiancé:

Dagmara: We never settle accounts, or rather we try not to settle accounts in front of other people, even friends.

Researcher: Why is that? We keep hearing this ...

Dagmara: Why? Because we believe it's our private matter, our personal issue. I would never say in front of our friends: 'You haven't given me back (my money)', or 'Now it's your turn to pay, because I paid for something earlier'. We come back home, and then we talk about it. But we never talk about it in front of our friends.

Moving in, and spending more time together, generates repeated financial transactions, so the model of paying each time becomes wearisome, and is gradually replaced with taking turns paying, while simultaneously monitoring each other's obligations. When debts grow, partners signal the need for settlement by saying, for instance, 'I bought groceries twice in a row, now it's your turn'. There is a shared understanding that each partner should assist in restoring balance. In the 50-50 model, debts inevitably emerge, followed by systematic attempts to settle accounts. As Zuzia, who lives in a rented flat with her boyfriend Piotr, says, it's about 'not having such a long-term obligation, one involving larger amounts of money'. 
Analysis of couples' financial diaries showed that significant expenses were settled on the day they were incurred, or the day after.

Precise accounting requires constant attention, even when taking turns. Ania and Kamil, engineers living in a rented apartment, use a spreadsheet to calculate and monitor who paid for what and how much is owed. They continuously monitor debts, and settle imbalances, as they appear. Ania says that when her debt to Kamil grows too fast, 'a little light goes off in my head', triggering an impulse to settle the debt quickly. Thus, the 50-50 model requires a constant flow of information about expenses, and a sense of fairness is generated, and sustained, through discussion. Regular updates ensure that current balances are known, and agreed.

Fairness in the 50-50 model is seen as justice based on equality, and independence; it involves constant care to avoid arguments about who paid more, and who spent less. When justifying these rules, couples underline their partnership, differentiating between this model, and a situation that could be called 'sponsoring'. The 50-50 model assumes gender neutrality: as a rule both partners should be equal and no one should have an advantage. 'We share like leftists, equally', says Mikołaj, a manager, about his arrangement with Marta, a PR specialist. He emphasises that their expenses are not divided into 'men's' and 'women's' spheres. In theory, the 50-50 model is based on simple, clear rules, but in practice, it faces challenges that make following the rules difficult. Sharing expenses equally works when partners have similar consumption patterns, and their grocery bills are consistently approximately the same amount. However, if consumption styles diverge, complications follow. Perhaps one partner buys 'fancy' food, while the other purchases ingredients for simple meals. Another important factor that challenges the $50-50$ model is income discrepancy, which is especially important when a couple plans activities, or purchases, that significantly exceed one partner's financial capacity. In this situation, the 'stronger' side either adapts to the 'weaker' partner by reducing consumption level (e.g. choosing cheaper holidays), or offers to overpay. Another mitigation strategy is simply to invite the partner out more often. However, giving a loan is a more unambiguous action: in the 50-50 model couples take care to settle debts as soon as possible, with the exact amount owed.

\section{Joint money and mutual obligation}

In this model, money is not divided into 'mine' and 'yours'; a couple treats all funds as jointly owned, though this does not necessarily mean they have shared bank accounts. Funds may be allocated to separate accounts, but still treated as pooled resources. The joint budgeting area includes current incomes, bills, debts, savings and investments. There is no settling of accounts between the partners; money is counted only in the context of the total household budget. This is how Janusz, married to Matylda (raising one child and expecting a second), describes joint money:

Janusz: If you're married, or you're in some kind of advanced relationship, then you should rather have joint money. I'm earning for you, and for myself. I share 
everything with you, including my apartment, and we should enjoy it together. We shouldn't hold it against each other if one of us spends more. I'm glad my wife doesn't reproach me for having gone on a trip to London. Theoretically she could do it and maybe I would understand that, but otherwise there should rather be a joint area.

In this model, fairness means solidarity, or financial jointness, and mutual obligation. Couples emphasised their common goals, and mutual support, with metaphors: 'we are like a single organism'; 'we put it all into a common pot'; 'we are in the same boat'; and 'we are on the same team'. Some women emphasised the symbolic significance of marriage in adopting joint money. Kasia recalls that before marriage, money was 'theoretically joint', but in practice, Maksymilian spent his money on himself, and his pleasures, while she spent hers on herself, while also covering household expenses. After marriage, this separation was erased; they adopted a shared budget. Post factum, Kasia considers the earlier financial separation into 'mine', and 'yours', as 'immature'. Other couples suggested that joint-money arrangements resulted from their decision to see themselves as 'partnerships' rather than separate individuals. Even married couples underlined the 'partnership' concept, arguing that commitment to their partner results from the financial arrangements they agreed upon, and not from the legal order that regulates the range of rights and obligations in a marriage.

Joint finance includes not only current, or planned, expenses, but also past debts. Ola (sales manager), and Lukasz (project manager), decided that the money received from their families as a wedding gift would be partially used to pay Łukasz's credit card debt. The couple wanted to begin their married life without either partner being burdened by past debts.

Łucja and Marian, who were engaged, decided that as they were planning a future together, they did not want Łucja to have to reduce her spending on account of a loan she had taken to renovate her flat (before meeting Marian). They agreed to refrain from certain expenses in order to pay off the debt quickly. In two other relationships, women used their own savings to settle their partners' past debts, to increase their household creditworthiness and to improve mortgage conditions. Adopting shared money means no more division into 'my', and 'your', money, and no division into 'my', and 'your', debts. 'Your debt' becomes 'our debt'.

Couples practising this model usually have children, or a mortgage, which necessitates changing their consumption practices. To make ends meet, they reduce their expenditures on entertainment, cultural events and holidays abroad. Simultaneously, couples begin saving, and planning capital accumulation (e.g. property investment), to ensure their children will have a good start in life, and won't need to take a mortgage. Having children, and trying to get a mortgage (or already having one), make couples more likely to accept financial support from their parents, who cover deposit costs, and support their grandchildren with cash, and goods. Owning a flat, and investing in children, become primary, positively 
valued goals supported by extended families, which justify money transfers from parents to their adult children's households.

Operating, and budgeting, jointly requires full income, and expense, transparency; among couples who use only a joint bank account, transparency is reinforced by Internet banking. Couples emphasise that jointness, and transparency, do not mean that one partner limits the other's expenses. However, in practice, partners discipline themselves (by deciding not to buy expensive clothes, for example). Having joint money means stricter individual discipline in budgeting household money, and clearly earmarking which expenses are necessary, and justified, and which are frivolous. Some couples use spreadsheets, with elaborate categories, and formulae, to determine household goals, such as saving for investment, or additional mortgage payments (Halawa and Olcoń-Kubicka, 2018).

The joint-money model considers external factors such as income discrepancy, income reduction or job loss. However, in practice, joint-money practitioners face numerous challenges to following these rules. First, full transparency limits individual freedom of consumption, including for spontaneous, unexpected gifts, which require attempts to hide extra funds, such as bonuses or rewards. Some couples solve this challenge by creating a small area of independence, supported by an additional bank account, which allows them to keep small secrets and buy things the partner does not approve of, such as junk food, yet another handbag or some gadget. Second, the joint-money model assumes that income discrepancies between men and women (among participants the rate was 60/40 for men) do not matter. Sometimes the joint bank account becomes an instrument for blurring income differences. However, control issues arose among some couples who decided to use a joint bank account. Although in theory couples claim to manage and control their money together, in practice one partner usually has greater control, and a final say about household expenditure. This results in significant self-discipline in spending for the common good of the household on the part of the controlled partner and greater freedom in occasional purchases by the controlling partner.

\section{Balancing equality and solidarity}

These two models of money allocation are driven by a pursuit of fairness, but in each case 'fairness' is defined by different norms about what is 'right', and what is not, in a particular moment. However, there are situations where the fairness is challenged, questioned and contested. These turning points may cause a shift from one model to another, or generate constant negotiation between partners about the appropriate criteria of fairness, without an agreement being reached.

Most joint-money couples in our study used the 50-50 model early in their relationship; it matched their needs at that time. However, they shifted from following this rule precisely towards balancing, and approximating, spending. Yet the 50-50 rule was maintained for regular expenditures such as rent, and bills, as well as for unique, but significant, expenses such as holidays abroad. Both partners participated equally in these expenses, covering them with their own funds. 
Moreover, couples moved away from precise cash settlements, or money transfers, and chose an exchange instead, such as rent for other instalments, or petrol for groceries. By quitting the 50-50 model, couples ceased to check receipts carefully, instead shifting to a mental monitoring of approximate equivalences. Joint-budgeting couples delegitimised their former 50-50 approach, rejecting arithmetic approaches to a relationship, because they found the precise settling of accounts was 'too blunt', and 'contradicts the idea of being together'. Furthermore, when moving away from a precise 50-50 model, couples' time horizon for settling accounts grows longer than one month. Thus, not only is the 'debt' settled mentally, without cash, but there is also more time to settle it: the relationship's temporal horizon expands. Couples assume that a general balance will be restored some time in the future. Just as settlement practices are replaced with mental calculations, couples begin to ignore small transactions, caring only that the final balance should be more or less fair. This is how Ola describes the imperceptible change in the arrangement she had with her future husband Lukasz:

Ola: We seemed to move smoothly into joint-money management. There were talks as well: 'How would it be - joint or separate accounts?' Later on, when we were not married but we were already adjusted - but not living together yet - we had joint money [...]. There wasn't a situation where we had separate money and then suddenly, after marriage, we had joint money. When you're seeing somebody, you don't count the money that much. This person is close to you and you know you love them you feel safe. You know you will be together even if you don't think about getting married. This money is sort of joint - it gradually gets transformed and nobody notices. It's a known fact that in the beginning everyone counts their own money, and nobody confesses to anyone how much money they have. But the more you get adjusted the more you talk. You start talking about money - about how much one earns - it's normal. You start making plans. The boundary between yours and mine simply gets blurred.

This gradual shift from one model to another, and the practical reasoning behind it, illuminate the differences observed by Supriya Singh and Jo Lindsay (1996) between cohabiting couples, who perceived money as separate and calculable; and couples in marriages, where money is shared and more nebulous. The expansion of the relationship's time horizon, and the shift from short-term to long-term commitments, also transforms exchanges within the household, and expectations of reciprocity (cf. Graeber, 2001: 220; Parry and Bloch, 1989: 24-25).

Among participants, as a relationship's time horizon lengthened, the area of joint obligations, and expenses, also expanded. Simultaneously, the sphere of independent funds shrank, though separate areas of influence and obligation might remain through divisions into 'my', 'your' and 'our' money. This pursuit of balance between participating in household expenses, and keeping separate funds, is usually supported by three bank accounts: both partners retain individual accounts, and a third is used by both, for joint expenses. For instance, both partners pay for their 
own clothes, and cosmetics, with their own money. 'We aren't each other's sponsors', Ania said, explaining the boundaries she and her husband Antoni observed between separate spending areas. They clearly divided personal, and joint, money; when shopping at IKEA, they separated goods with a divider into two more or less equal parts. In practice, following the rule of personal, and joint, areas of expenses results in a number of practical challenges. Couples often 'borrow' money from the joint account, and sometimes pay it back, but sometimes do not. Small expenses are strategically ignored, as partners 'forget' about returning certain amounts. Ania and Antoni stressed that when one of them was buying something, and was paying with their joint-account card, the money did not have to be returned if the expense could be qualified as a household expense, but if it served only one of the partners then the payment had to be settled. However, that rule did not last long. Tired of tracking expenses, after 6 months they began to consider sharing their funds completely, since they had bought and renovated a flat, and were expecting a baby in 2 months.

This research suggests the main factor leading to significant expansion of joint budgeting is having a first child together. Even if couples stress marriage, or taking out a mortgage, as turning points in expanding their joint financial area, the presence of a third person in the household, whose needs must be covered, prompts pooling of resources, and increases solidarity between partners. This is also a crucial reason for starting a joint account among cohabiting couples, as Krysia and Jurek suggest:

Krysia: When we started to discuss taking out a mortgage, we had already talked about having a joint account. Even if the bank hadn't imposed it on us, we were planning to do it, because in our reasoning - I don't know if it was a good reasoning, but we thought it would facilitate our functioning.

Jurek: We wanted to open a joint account, because the baby was already on its way. Krysia: Yeah, besides, we were living together, and we had a household, but after the baby was born we really started to have a joint household. We came to the conclusion that it would be easier for us to control this money if we had one account.

Mortgages, and getting married, which are important factors in expanding a relationship's time horizon, also contribute to expanding the joint financial area. Their impact was observed among couples who were planning to marry, or buy a house. Such plans encourage couples to begin mentally pooling funds that are in separate, private accounts. Anna and Franek, who are married, live in a flat owned by Anna; each has their own personal savings, which are treated as funds for their personal expenses. However, as they discuss plans to purchase a larger flat, they begin to combine their savings mentally, which includes the money they will receive from selling Anna's flat. The gradual expansion of their joint budgeting area extends beyond current earnings, and spending, to include personal savings and wealth.

Future expectations (Beckert, 2016) influence money practices in the present, shaping moral reasoning about what one can, or cannot, do with money that is 
allocated for joint spending in the future. A student couple, Kamil and Dagmara, illustrate this phenomenon. After becoming engaged, they decided to assign a certain percentage of their salaries to joint savings, which were earmarked for a large, costly wedding in the future. Kamil's unexpected purchase of a motorbike created a serious conflict. Dagmara believed that their mutual commitment had been compromised and that Kamil had spent part of his regular wage that should have gone to their joint savings. But when Kamil revealed that he had bought the motorbike with money he had earned from overtime work on weekends and evenings, and that the joint savings remained intact, the conflict disappeared. Other couples create and maintain a zone of indeterminacy (Lainer-Vos, 2013), which permits occasional irregularities, such as buying something without a partner's consent. Antoni B. and Blanka, who are married, describe an arrangement that involved joint savings, while simultaneously allowing some financial independence:

Antoni B.: Until we took out the mortgage, each of us had a separate account, but we were already aware that the money we had in those accounts was joint.

Blanka: It was joint money, yes.

Antoni B.: We already had that awareness. But it was as if we had a certain freedom the freedom in our wallets.

Blanka: Yes. One could still buy something secretly.

The possibility of keeping an autonomous budgeting area, outside a partner's control, is one reason why couples keep their personal accounts even while gradually expanding their joint finances. Balance is the governing rule here, and concerns harmony between solidarity with the partner, and keeping some financial independence.

Maintaining balance is also about avoiding full transparency, which is part of the joint-money model. However, some couples are also concerned about avoiding the temptation to exert control over a partner's expenditures. Ania and Antoni, a married couple living in an apartment bought on credit, discuss this problem:

Researcher: Why not have a joint account? Marriage, joint account...

Ania: It's hard to make a surprise for another person, as they would see each move. Besides, I don't have to hide each purchase; I don't necessarily have to confess to Antoni that I bought mascara. Why should he know how much it costs? His heart would hurt, my little miser.

Researcher: So, sometimes it's better not to know certain things?

Ania: It's better not to know in order to avoid conflicts. It's cool to save on your own. I don't know why it gives me such pleasure that I earn that money and when I want to buy something nice I can say, 'I've got 1500 zlotys'. 'How come?' 'I was saving'. That's so cool, but otherwise I would have no influence over that.

Antoni: You wouldn't manage to save as two people...

Ania: No, that would be... I would be spying on his every move, I wouldn't want that. 
Antoni: No, one expects some kind of privacy in many domains, including finance.

Researcher: Finance is a private matter?

Ania: A little bit, yes.

Antoni: It's kind of private for me, because I go to work, I earn that money, and I'm happy when a transfer from my employer comes and I manage it on my own. It's mine, and we chip in afterwards.

Somewhere in between using the 50-50 rule, and adopting the joint-money model, couples struggle to find an 'Aristotelian golden mean', as Antoni described it. Such arrangements are not about precisely equal division, and calculations, but about embracing full transparency, and commitment. These interim arrangements are about fulfilling both partners' needs without making either feel exploited, and finding that balance becomes harder when couples differ in their consumption habits. A significant purchase made by one partner, followed by a purchase for the same amount by the other partner ('to make it fair'), often results in surpassing the joint monthly budget. However, sometimes imbalances involve long-term capital assets, not just tit-for-tat personal purchases. For example, Piotrek and Daria, who are engaged, had to decide whether it was just and fair to invest in a flat owned only by one partner. This couple decided - while renovating and furnishing a flat that Piotrek formally owned - that Piotrek would cover the renovation and furnishing of the flat, such as the kitchen fittings, while Daria would invest her money in movable furniture and objects she could take in case of a breakup.

When striving for balance, couples consider external factors and, instead of engaging in calculation, they perform a 'qualculation', a situation-sensitive evaluation when calculation is no longer possible (cf. Cochoy, 2008: 26). These 'qualculations' create blurred areas allowing couples to avoid feelings of unfairness, while simultaneously ameliorating inequalities. Such blurred budgeting areas permit partners to avoid precise settlements if one of them is unable to earn enough money to cover household budgetary obligations. When one partner struggles to pay off a loan, or experiences temporary unemployment or an illness, the other partner takes over, meeting daily expenses several times in a row. In such situations, partners also give each other informal loans, whose size may grow over time, with payback periods that gradually lengthen, since there is no need (or capacity) to pay the debt quickly. At the same time, a tacit understanding emerges that it might not be necessary to settle the debt at all. Thus 'borrowing' becomes 'helping', or simply 'giving'.

Relational work (Zelizer, 2012) is certainly about generating meaning, but as my analysis above shows, sometimes relational work is about blurring boundaries as well. When couples face challenges in strictly following a 50-50 or joint-money rule, they sometimes decide to avoid assigning unambiguous meanings to each and every transaction. Rather, they engage in what Lainer-Vos (2013) has called (in a different context) 'blurring practices', which allow couples to avoid defining situations in categories of domination or being dominated, and thus to continue a relationship they feel is based on fairness. Income discrepancy, temporary 
unemployment or the lack of earnings it entails inspire a range of such blurring practices, which couples use to avoid confrontation. Moreover, these efforts mitigate the significance of income imbalance, and consequently, of potential inequality within the relationship. However, the preoccupation with inequality remains.

As our research progressed, some women revealed that they had agreed to pool resources, and use a joint account, only because they wanted to avoid settling accounts by the 50-50 rule, as such a settlement would have put them in an inferior position given their lower income. At the same time, full transparency in spending makes these women miss their former independence. However, having children makes it hard for Polish couples to return to egalitarian practices - not only with respect to housework (cf. Żadkowska and Szlendak, 2016), but, as my evidence shows, with respect to money. Among participants using a joint-money model, only Ola and Lukasz (married, no children) decided to withdraw from joint budgeting and reinstate spheres of financial independence. The step was initiated by Ola, who was promoted, and given a raise, at work but who was not 'feeling that raise' as her money was in a joint account. This move towards financial independence was not without its own problems, however:

Ola: Something might break between us, as we will have separate accounts. There could be something like someone might pay more and expect returns, or - I don't know - someone might say, 'I paid a hundred zlotys more for a taxi a month ago'. [...] I don't know how it's going to be. Should we buy things by paying with the joint money or each one separately? Or should we pay for household (expenses) with the main money, but for a face cream with mine? One is bad and so is the other.

This tension, or even struggle, between equality, independence and solidarity, becomes more apparent among couples who have not reached an agreement, or who have conflicting visions about what their ideal financial arrangement should be.

Krzysztof and Ania, the couple mentioned at the start of this article, are striving to find a way to organise their financial life. While he insists on sharing their obligations equally, in closer to a 50-50 model, she would prefer joining their money completely, as they are a family raising two children together. Several times over the course of our study, they openly discussed the discrepancy between their approaches to money management. While the above evidence shows how the idea of fairness changes over time in a household, as do the strategies for restoring balance, this case suggests there is also much confusion about the rules of fairness, or the fairness of the rules, especially in connection with turning points in a couple's life together. Moreover, such negotiations are not always successful, though the relationship continues.

\section{Conclusion}

This article has explored the normative concerns shaping the negotiation of financial arrangements of young middle-class couples in Poland. I have shown how, 
through relational work, couples use both moral and economic arguments to debate the 'right' use of money in their household. I have argued that the practical division of money into 'mine', 'yours' and 'ours' reflects the notion of what couples running households together consider morally right. The focus on participants' moral feelings and pragmatic beliefs about what is appropriate and moral (Fourcade, 2017; Fourcade and Healy, 2007; Sayer, 2011) revealed that for young, double-income, urban, middle-class couples in Poland, the 'right' use of domestic money is connected with fairness, though the definition of what is 'fair' can shift greatly over a relationship's course. Then, I showed the underlying mechanisms that shape changes in money practices related to specific life changes and pointed out the importance of normative concerns in the household. This research shows that fairness is a fragile accomplishment, a dynamic process. Household financial arrangements are dynamic, as the rules of fairness are questioned, challenged and contested in relation to significant life changes. To determine what is fair at a particular moment, couples create boundaries between what is calculated and not calculated, explicit and implicit, secret and transparent, gender-neutral and gender-sensitive, universal and particular.

Couples' relational work when negotiating these rules of categorisation, division and budgeting show that in setting the boundaries of 'mine', 'yours' or 'ours', couples try to navigate between market and intimate logics. Preoccupied with money's corrosive potential (Zelizer, 2005), and constrained by moral beliefs and expectations, couples monitor their mutual actions to determine what is 'fair' and 'unfair'. As they perform this moral boundary drawing (Lamont, 1992; Sayer, 2005), not only do they negotiate between autonomy and solidarity in their relationship, they also establish their relations with the outside world. These findings reinforce the importance of external socio-economic, and cultural, factors in shaping relational work (Bandelj, 2015). For instance, household financial arrangements are strongly influenced by a couple's housing situation, and the Polish property market, which drives young people towards mortgages (Halawa, 2015); income inequality between men and women in the labour market; and social policies that provide 1-year paid maternity leave for women. However, couples try to create a vision of themselves as financially autonomous, operating in a domestic sphere distinct from the outside world. Thus, the pursuit of 'fairness' becomes a private issue, regulated by mutually shared feelings, independent of outside social and economic factors. Moreover, in the respondents' views, achieving fairness is about striving to generate the mutual feeling that their financial arrangement is clear, right and fair. In practice, money and financial arrangements become a way of demonstrating moral respectability by conformity to particular norms (equality, independence and solidarity), as well as to gender roles and expectations.

The evidence gathered among the young urban middle class shows that as the relationship progresses, couples change their money practices and their understanding of fairness. In the process of building mutual trust, couples navigate from fairness understood as equality and independence, through a balance between independence and solidarity, towards plain solidarity understood as financial 
jointness and mutual obligation. Events that prompt these shifts include having a first child together, taking out a mortgage, and marriage. Family and ownership remain important points of reference for life strategies among the young middle class in Warsaw. I have shown how the pursuit of fairness - and egalitarian claims driven by the idea of 'partnership' - is challenged by inequalities and confronted with the pragmatics of everyday life. Further studies on conflict situations, including breakups and divorces, might reveal more about household moral economy, when money and family issues have to be negotiated and established anew. Therefore, more research should be conducted into family-market relations, not only in the post-communist countries but also in other modern societies operating in a market economy in late capitalism.

\section{Acknowledgements}

Thanks are due to my colleagues from the Max Planck Partner Group for the Sociology of Economic Life: Mateusz Halawa and Marcin Serafin for their insightful comments to early versions of this article. I am also very grateful to Mateusz Halawa for conducting the interviews together and Małgorzata Łukianow for her research assistance in coding the material. This article was completed during a visiting research stay at the Max Planck Institute for the Study of Societies. Thanks to my colleagues in Cologne, for their thoughtful comments and critiques. Early version of this article was presented at the workshop 'Contested Futures and Temporalities of Capitalism' in 2018. I am very thankful for the comments received then, as well as for further critiques offered by Jens Beckert, Daniel Fridman, Andrew Sayer, Filip Schmidt, Hadas Weiss, Joanna Zalewska and Magdalena Żadkowska. I am also very thankful for the comments and suggestions offered by the editors of this special issue: Sandy Ross and Christopher Swader, as well as by an anonymous reviewer.

\section{Declaration of Conflicting Interests}

The author(s) declared no potential conflicts of interest with respect to the research, authorship and/or publication of this article.

\section{Funding}

The author(s) disclosed receipt of the following financial support for the research, authorship and/or publication of this article: This work was supported by the National Science Centre, Poland under (grant number DEC-2013/09/B/HS6/03426) and by the Max Planck Partner Group for the Sociology of Economic Life at the Institute of Philosophy and Sociology of the Polish Academy of Sciences.

\section{References}

Bandelj N (2015) Thinking about social relations in economy as relational work. In: Aspers P and Dodd N (eds) Re-Imagining Economic Sociology. Oxford: Oxford University Press, pp. 227-251.

Bandelj N, Wherry FF and Zelizer V (eds) (2017) Money Talks: Explaining How Money Really Works. Princeton, NJ: Princeton University Press. 
Beckert J (2016) Imagined Futures. Fictional Expectations and Capitalist Dynamics. Cambridge, MA: Harvard University Press.

Burgoyne CB (1990) Money in marriage: How patterns of allocation both reflect and conceal power. The Sociological Review 38(4): 634-665.

Carruthers BG and Espeland WN (1998) Money, meaning, and morality. American Behavioral Scientist 41(10): 1384-1408.

Cochoy F (2008) Calculation, qualculation, calqulation: Shopping cart arithmetic, equipped cognition and the clustered consumer. Marketing Theory 8: 15-44.

Douglas M (1991) The idea of a home: A kind of space. Social Research 58(1): 287-307.

Dunn EC (2004) Privatizing Poland: Baby Food, Big Business, and the Remaking of Labor [Culture and Society After Socialism]. Ithaca, NY: Cornell University Press.

Fourcade M (2017) The fly and the cookie: Alignment and unhingement in 21-st century capitalism. Socio-Economic Review 15(3): 661-678.

Fourcade M and Healy K (2007) Moral views of market society. Annual Review of Sociology 33(1): 285-311.

Galasińska A and Galasiński D (2010) Living between history and the present: The Polish post-communist condition. In: Galasińska A and Galasiński D (eds) Discourse Approaches to Politics, Society and Culture. Amsterdam: John Benjamins Publishing Company, pp. 1-20.

Giza-Poleszczuk A and Poleszczuk P (2004) Partnership, marriage and children - Cultural differentiation of attitudes. In: Jasińska-Kania A and Marody M (eds) Poles Among Europeans. Warszawa: Scholar, pp. 199-228.

Graeber D (2001) Toward an Anthropological Theory of Value: The False Coin of Our Own Dreams. New York; Basingstoke: Palgrave Macmillan.

Halawa M (2015) In new Warsaw: Mortgage credit and the unfolding of space and time. Cultural Studies 29: 707-732.

Halawa M and Olcoń-Kubicka M (2018) Digital householding: Calculating and moralizing domestic life through homemade spreadsheets. Journal of Cultural Economy 11(6): 514-534.

Ibragimova D and Guseva A (2017) Who is in charge of family finances in the Russian twoearner households? Journal of Family Issues 38: 2425-2448.

Kenney CT (2006) The power of the purse: Allocative systems and inequality in couple households. Gender \& Society 20(3): 354-381.

Lainer-Vos D (2013) The practical organization of moral transactions: Gift giving, market exchange, credit, and the making of diaspora bonds. Sociological Theory 31(2): 145-167.

Lamont M (1992) Money, Morals, and Manners: The Culture of French and American UpperMiddle Class. Chicago, IL: University of Chicago Press.

Marody M (1991) Mieć albo być. In: Mucha J, Skapska G, Szmatka J, et al. (eds) Spoleczeństwo polskie u progu przemian. Wrocław: Zakład Narodowy im. Ossolińskich, pp. 29-43.

Marody M (1995) Life strategies in the emerging capitalist economy and the role of gender. Polish Sociological Review 110: 103-111.

Marody M and Giza-Poleszczuk A (2000) Changing images of identity in Poland: From the self-sacrificing to the self-investing woman? In: Gal S and Kligman G (eds) Reproducing Gender: Politics, Publics, and Everyday Life After Socialism Princeton, NJ: Princeton University Press, pp. 151-175.

Miller D (2005) A Theory of Shopping, reprint edn. Cambridge: Polity Press. 
Olcoń-Kubicka M (2016) Financial arrangement as a reflection of household order. Polish Sociological Review 196(4): 477-494.

Olcoń-Kubicka M and Halawa M (2018) Making a living: How middle-class couples in Warsaw start and practice a household. Kultura i Spoleczeństwo LXII(4): 91-111.

Pahl J (1989) Money and Marriage. Basingstoke: Palgrave Macmillan.

Parry J and Bloch M (eds) (1989) Money and the Morality of Exchange. Cambridge. Cambridge University Press.

Patico J (2005) To be happy in a Mercedes: Tropes of value and ambivalent visions of marketization. American Ethnologist 32: 479-496.

Pellandini-Simányi L (2014) Consumption Norms and Everyday Ethics. London: Palgrave Macmillan.

Pellandini-Simányi L (2016) Everyday consumption norms as discourses of the good life in pre-socialist and socialist Hungary. Journal of Consumer Culture 16: 699-717.

Rawls J (1971) A Theory of Justice. Cambridge, MA: Harvard University Press.

Rona-Tas A and Guseva A (2014) Plastic Money: Constructing Markets for Credit Cards in Eight Postcommunist Countries. Stanford, CA: Stanford University Press.

Ross S (2014) What is ambiguous about ambiguous goods? Journal of Consumer Behaviour 13(2): $140-147$.

Sayer A (2005) The Moral Significance of Class. Cambridge: Cambridge University Press.

Sayer A (2011) Why Things Matter to People: Social Science, Values and Ethical Life. Cambridge: Cambridge University Press.

Schor JB, Slater D, Zukin S, et al. (2010) Critical and moral stances in consumer studies. Journal of Consumer Culture 10(2): 274-291.

Singh S (1997) Marriage Money: The Social Shaping of Money in Marriage and Banking. St Leonards, NSW, Australia: Allen \& Unwin.

Singh S and Lindsay J (1996) Money in heterosexual relationships. Journal of Sociology 32(3): 57-69.

Slater D (2009) The ethics of routine: Consciousness, tedium and value. In: Shove E, Trentmann F and Wilk R (eds) Time, Consumption and Everyday Life: Practice, Materiality and Culture. Oxford: Berg, pp. 217-230.

Sonnenberg SJ (2008) Household financial organisation and discursive practice: Managing money and identity. The Journal of Socio-Economics 37(2): 533-551.

Steiner P (2015) The organizational gift and sociological approaches to exchange. In: Aspers P and Dodd N (eds) Re-Imagining Economic Sociology. Oxford: Oxford University Press, pp. 275-298.

Tóth AH and Simányi L (2006) Cultural values in transition. Society and Economy 28: $41-59$.

Vogler C (1998) Money in the household: Some underlying issues of power. The Sociological Review 46(4): 687-713.

Vogler C and Pahl J (1994) Money, power and inequality within marriage. The Sociological Review 42(2): 263-288.

Warde A (2017) Consumption: A Sociological Analysis. New York: Palgrave Macmillan.

Wherry FF (2016) Relational accounting: A cultural approach. American Journal of Cultural Sociology 4(2): 131-156.

Wherry FF (2017) How relational accounting matters. In: Bandelj N, Wherry FF and Zelizer V (eds) Money Talks: Explaining How Money Really Works. Princeton, NJ: Princeton University Press, pp. 57-69. 
Żadkowska M and Szlendak T (2016) Egalitarian capital gained in Norway or brought from Poland? Experiences of migration and gender equality among Polish couples in Norway. In: Ducu V and Telegdi-Csetri A (eds) Managing "Difference" in Eastern-European Transnational Families. Frankfurt am Main: Peter Lang, pp. 91-112.

Zalewska J (2017) Consumer revolution in people's Poland: Technologies in everyday life and the negotiation between custom and fashion (1945-1980). Journal of Consumer Culture 17(2): 321-339.

Zaloom C (2015) A moral history of the household budget. Report, Department of Anthropology Colloquium, Washington University in St. Louis, St. Louis, MO, April.

Zelizer V (1997) The Social Meaning of Money. Princeton, NJ: Princeton University Press.

Zelizer V (2005) The Purchase of Intimacy. Princeton, NJ: Princeton University Press.

Zelizer V (2011) Economic Lives: How Culture Shapes the Economy. Princeton, NJ: Princeton University Press.

Zelizer V (2012) How I became a relational economic sociologist and what does that mean? Politics \& Society 40(2): 145-174.

\section{Author Biography}

Marta Olcon-Kubicka is an associate professor at the Institute of Philosophy and Sociology of the Polish Academy of Sciences. Her work focuses on cultural analyses of economic life and on ethnographic research into money practices in households. She was a Principal Investigator in the project 'Practices of handling money in close relationships in young family households' (2014-2017). She is currently leading the research project 'Intergenerational transactions: relational work and moral frames in transfers of wealth from parents to their adult children'. 